\title{
Os grilhões do patrimônio: reflexões sobre as práticas do Iphan relacionadas aos quilombos
}

\author{
Beatriz Accioly Vaz ${ }^{1}$ \\ Instituto do Patrimônio Histórico e Artístico Nacional
}

\section{Resumo}

A partir da mudança de perspectivas incorporada no texto da Constituição Federal de 1988, o Instituto do Patrimônio Histórico e Artístico Nacional (Iphan), responsável pela proteção e salvaguarda do patrimônio cultural no Brasil, precisou responder às demandas surgidas pelo reconhecimento dos bens referenciais da matriz afrodescendente, dentre os quais aqueles relativos às comunidades quilombolas. Assim, o tombamento e, a partir do ano 2000, o registro, instrumentos da política de patrimônio nacional de uso privativo do Iphan, passaram a ser acionados como forma de reconhecimento, proteção e salvaguarda desses bens. Dentro desse universo, o presente artigo propõe uma reflexão sobre como o patrimônio cultural quilombola vem sendo tratado nesse campo, buscando identificar os conflitos e as possibilidades existentes no reconhecimento de direitos coletivos dessas comunidades através das políticas patrimoniais. Através dessa reflexão, as formas de incorporação do patrimônio "não consagrado" pelo Iphan e a separação do campo do patrimônio cultural em duas áreas distintas - material e imaterial - são problematizadas.

Palavras-chave: Patrimônio cultural. Quilombos. Instrumentos de proteção.

\section{The shackles of heritage: reflections on the IPHAN's practices related to quilombolas communities}

From the change of perspective embodied in the Constitution of 1988, the Institute of Historical and Artistic Heritage (Iphan), responsible for the protection and safeguarding of cultural heritage in Brazil, had to meet the demands arising from the 
recognition of the assets of reference array of African descent, among those related to quilombolas communities. Thus, the tombamento and, from 2000 , the registry, as instruments of national heritage policy for private use Iphan, have been triggered as forms of recognition, protection and safeguard these assets. Within this universe, this article proposes a reflection on how cultural heritage of quilombolas communities have been treated in the field, seeking to identify the conflicts and possibilities in the recognition of collective rights of these communities through cultural heritage policies. Through this reflection, forms of equity merger "unconsecrated" by Iphan and separation of the field of cultural heritage in two distinct areas - tangible and intangible - are problematized.

Key words: Cultural heritage. Quilombos. Instruments for protection.

No Brasil, a política federal de patrimônio cultural surge no final da década de 1930 com a sanção do Decreto-Lei 25/1937, que cria o Serviço do Patrimônio Histórico e Artístico Nacional e institui o tombamento como instrumento de proteção e preservação. Tendo como impulso a preocupação com o estado de abandono das cidades coloniais e o anseio pela preservação de monumentos e objetos representativos da matriz lusa e da elite econômica e religiosa, durante muito tempo foram deixados de lado bens referenciais de outros segmentos e grupos formadores da sociedade brasileira. Dentro desse contexto, as referências culturais de matriz afrodescendente começam a ser inseridas de maneira mais ampla no campo das práticas e políticas de preservação e salvaguarda do Iphan apenas na década de 1980. Antes disso, o tombamento do Museu da Magia Negra, em 1938², no Livro do Tombo Arqueológico, Etnográfico e Paisagístico, era o único representativo desse segmento. Em 1986, o tombamento de dois bens foi de grande relevância simbólica para a mudança de perspectiva que começa a ser instaurada: o tombamento da Serra da Barriga, antigo Quilombo dos Palmares, em Alagoas, e do Terreiro da Casa Branca, templo religioso do candomblé na Bahia. O primeiro desses reconhece oficialmente uma das referências mais importantes em âmbito nacional para o Movimento Negro no Brasil, símbolo da resistência contra o regime escravocrata; o segundo reconhece, pela primeira vez, um bem referencial de uma religião afro- 
brasileira - o candomblé - em contraposição aos inúmeros tombamentos de igrejas católicas.

A Constituição Federal de 1988 representou um marco no reconhecimento de direitos diferenciados de populações tradicionais e na ampliação do campo do patrimônio cultural, até então referenciado predominantemente no patrimônio de "pedra e cal". Nesse contexto, os grupos autoidentificados como remanescentes de quilombos passaram a ser amparados pela legislação no que diz respeito à titulação de suas terras e reconhecimento de direitos culturais, previstos nos artigos $215 \mathrm{e}$ 216. A respeito do reconhecimento das referências culturais afrodescendentes, a Constituição prevê em seu artigo 215 a proteção das manifestações culturais afrobrasileiras ${ }^{3}$ e estabelece, no 5o parágrafo do artigo 216 , que "ficam tombados todos os documentos e os sítios detentores de reminiscências históricas dos antigos quilombos". Ao mesmo tempo, o artigo 68 do Ato das Disposições Constitucionais Transitórias prevê que o estado reconhecerá a propriedade definitiva das terras que estejam ocupadas pelos "remanescentes das comunidades dos quilombos". Temos assim, no texto constitucional, dois artigos distintos que tratam especificamente da questão dos quilombos, além de um terceiro que a aborda dentro da rubrica genérica das políticas culturais.

No entanto, na proposta inicial do artigo constitucional que trataria da questão dos quilombos feita pelo Deputado Carlos Alberto de Oliveira durante a Constituinte, 0 tombamento estava atrelado ao reconhecimento da posse das terras das comunidades, sendo que esse recairia sobre as terras ocupadas pelas comunidades quilombolas e sobre os documentos referentes à história dos quilombos no Brasil. Tal proposta acabou sendo desmembrada e modificada, ficando o tombamento restrito aos documentos e sítios detentores de reminiscências históricas dos antigos quilombos na parte que fala sobre a cultura no corpo da Constituição; e a questão fundiária, exilada no corpo "transitório" dessa. Arruti aponta para a questão política que estava em jogo nesse momento, considerando que a configuração final desses artigos era

Uma evidência de que a temática da população negra e a cultura não gozam apenas de uma "afinidade eletiva", mas de que o campo da cultura era, até então, o próprio limite 
permitido ao reconhecimento público e político dessa temática. E não seria o texto do "artigo 68" que mudaria isso, mas a sua captura por parte do movimento social. (ARRUTI, 2003, p.11)

O direito ao reconhecimento da propriedade das terras pelos remanescentes das comunidades de quilombos foi, então, incorporado por parte do movimento social como uma de suas bandeiras. Simultaneamente, tratava-se de compreender e dar sentido aos termos utilizados para definir determinadas comunidades como "remanescentes de quilombos" ou "quilombolas", tanto do ponto de vista político, como também do ponto de vista acadêmico. Com isso, operou-se a ressemantização dos termos quilombo e quilombola que, a partir de uma perspectiva dinâmica, passaram a tratar os grupos assim reconhecidos pelo que eles de fato são atualmente e não os tomando como resquícios ou fragmentos de um passado congelado. Como bem definido no documento elaborado pelo Grupo de Trabalho sobre Comunidades Negras Rurais da Associação Brasileira de Antropologia (Abant),

Contemporaneamente, portanto, o termo quilombo não se refere a resíduos ou resquícios arqueológicos de ocupação temporal ou de comprovação biológica. Também não se trata de grupos isolados ou de uma população estritamente homogênea. Da mesma forma, nem sempre foram constituídos a partir de movimentos insurrecionais ou rebelados, mas, sobretudo, consistem em grupos que desenvolveram práticas cotidianas de resistência na manutenção e reprodução de seus modos de vida característicos e na consolidação de um território próprio. (Abant, 1994, p. 1)

Assim, não caberia ainda hoje restringir, em referência a essas populações, os significados do termo quilombo a uma definição do período colonial que se resumiria a "lugar de escravos fugidos". Visto que esses territórios são "vivos" e mantêm-se, resistindo às forças dissipadoras e opressoras, recriando suas formas de ser e de manifestar suas culturas. Tal perspectiva foi sendo gradualmente construída e apropriada pelos atores envolvidos nesse processo de reconhecimento e identificação, constituindo-se como um discurso de positivação do termo quilombo que se insere em disputas políticas mais amplas, relacionadas à questão agrária e à situação dos negros no país. Os órgãos governamentais, por sua vez, responsáveis por gerir e implementar as políticas públicas relacionadas a essas populações e 
garantir os direitos previstos na Constituição, precisaram se organizar e criar normas que orientassem suas ações.

Nesse sentido, foi criada, em 1994, a Subcomissão de Estudos e Pesquisas, formada por técnicos da Fundação Cultural Palmares (FCP) e do então Instituto Brasileiro do Patrimônio Cultural (IBPC) ${ }^{4}$, com o objetivo de cumprir as disposições do $5^{\circ}$ parágrafo do art. 216. Como consta em ofício do diretor de Estudos, Pesquisas e Projetos da FCP ao Subprocurador Geral da República, caberia a essa subcomissão:

(...) identificar, inventariar e propor o tombamento daqueles sítios e populações que descendem da cultura afro-brasileira, que deverão, após o laudo antropológico, ser reconhecidos como remanescentes de quilombos por meio da Fundação Cultural Palmares, tão logo se regularize o art.68. (1994 apud ARRUTI, 2005, p.83)

Então, a princípio FCP e IBPC desenvolveriam um trabalho em conjunto e, o que deve ser destacado, os artigos constitucionais que abordam a questão quilombola seriam tratados de forma articulada. Sobre isso, Arruti observa que, nesse momento, predominava "a noção historicizante, arqueológica e voltada para a noção de patrimônio histórico", em detrimento da concepção dos "quilombos contemporâneos" (ARRUTI, 2006, p.83).

Essa noção, marcada por uma concepção de patrimônio "histórico", ao invés de "cultural", também estava presente no parecer DEPROT 47/98, que buscava a conceituação e normatização da questão do tombamento dos quilombos no âmbito do Iphan. Nesse parecer, a atuação do Iphan estava restrita às situações em que fossem encontrados vestígios materiais de existência dos antigos quilombos, sendo esses concebidos como:

(...) as comunidades autoexcluídas da sociedade nacional durante o período colonial até a abolição da escravatura, formados originalmente por negros escravos fugidos das áreas urbanas ou rurais onde existiam práticas de exploração escravista. (Iphan, 1998, p.7)

Não se considerava a concepção contemporânea de quilombo, baseada não na origem desse, mas na forma presente como seus membros se identificam e marcam 
distinções em relação a outros grupos e à sociedade envolvente. Tampouco considera-se que mesmo os quilombos "formados originalmente por negros escravos fugidos" poderiam ser uma comunidade contemporânea, que se manteve em um território específico reproduzindo suas formas próprias de sociabilidade. $O$ foco estava nos "vestígios", naquilo que restara de uma coletividade que não mais existia. Por essa perspectiva, negava-se a contemporaneidade dos quilombos e, por consequência, o comprometimento das políticas patrimoniais com esses grupos. Tratava-se mais de uma atuação de cunho arqueológico e histórico, desprovida de interlocutores. Recentemente, esse parecer vem sendo revisado, e o tombamento dos quilombos volta a ser objeto de discussão.

Em seu artigo Tombamento dos quilombos: atualizando a discussão, Dalmo Vieira, ex-diretor do Departamento de Patrimônio Material do Iphan, ao se debruçar sobre os artigos constitucionais que tratam especificamente da temática dos quilombos estabelece uma delimitação do que seria a competência do Iphan:

Pelo exposto, existem caracterizações e providências diferentes nos dois artigos da Constituição que tratam do assunto. Cabe ao Iphan definir o que são os antigos quilombos e onde estão, com a finalidade de cumprir o que determina a Constituição, isto é, tombá-los e inscrevê-los nos respectivos Livros do Tombo. Distintamente, o disposto acerca das comunidades quilombolas

determina a emissão de posse da terra, que só pode ser efetivada pelos órgãos com competência para tal. (VIEIRA FILHO, s. d., p.1, grifo meu)

No trecho em questão é enfatizada a distinção entre 0 ato administrativo do tombamento, instrumento reservado ao Iphan em âmbito federal, e a emissão de posse da terra, que caberia nesse caso ao Instituto Nacional de Colonização e Reforma Agrária (Incra), como previsto no Decreto 4887/2003. Ao longo do artigo, o autor realiza, então, uma revisão da discussão acerca do tombamento dos "antigos quilombos", concluindo que o estabelecido no parecer DEPROT 47/98 deveria ser revisto, tendo em vista as novas significações do termo. Desse modo, sugere que sejam consideradas como "reminiscências históricas dos antigos quilombos":

1 - As comunidades remanescentes de quilombos formadas por escravos negros fugidos até 13 de maio de 1888 como forma de resistência ao regime escravista; 
2- Comunidades remanescentes de senzalas, oriundas de escravos negros que habitavam as senzalas na época de escravidão e que com a Abolição foram beneficiários de doação das terras ou que permaneceram nelas, ou ainda, aquelas comunidades criadas por negros libertos como forma de reestruturação sócio/cultural decorrentes da Lei Áurea;

3- Os núcleos formados até meados do século XX, predominantemente por descendentes de escravos, como decorrência dos rearranjos sócio/econômico/culturais diretamente decorrentes da abolição da escravidão no Brasil. (VIEIRA FILHO, s.d., p. 8)

Ora, o autor não percebe que com essa nova conceituação, distintamente do que sugere no trecho citado anteriormente, os "antigos quilombos" serão - em sua maioria - as próprias "comunidades quilombolas", grupos contemporâneos, passíveis de terem suas terras tituladas pelo Incra. Perpetua, ainda, uma abordagem histórica e arqueológica do patrimônio que permite a restrição da atuação do órgão, sugerindo o tombamento do solo - "o local de vivência dos antigos quilombolas e não seus sucedâneos arquitetônicos de qualquer natureza" (VIEIRA FILHO, s.d., p. 9) como forma de reconhecimento do passado desses grupos que foram marcados pela escravidão. Não se colocando em questão os quilombos pensados como grupos contemporâneos, dinâmicos, com anseios em relação à preservação de suas referências culturais e manutenção de seus territórios.

Destaca-se que até o presente foram tombados apenas dois quilombos - a Serra da Barriga, antigo Quilombo dos Palmares, e os remanescentes do antigo Quilombo do Ambrósio -, não ocupados atualmente por populações que se reconhecem como quilombolas, ou remanescentes de quilombo, mas territórios historicamente consagrados como lugares em que existiram quilombos, na concepção mais restrita do termo. Apesar disso, existem processos de tombamento no Iphan, abertos desde a década de 1990, relativos a quilombos contemporâneos certificados pela Fundação Cultural Palmares. Percebem-se, com isso, as dificuldades do órgão em pôr em prática tal preceito constitucional e articular o instrumento do tombamento em contextos em que as comunidades quilombolas não são "vestígios" ou "marcas de um passado", mas coletividades vivas.

Por outro lado, o patrimônio cultural "de natureza imaterial", que passa a ser reconhecido pelo Iphan a partir do Decreto 3.551/2000, é expressivamente representativo da matriz africana. O Jongo do Sudeste, o Samba de Roda do 
Recôncavo Baiano, o Tambor de Crioula do Maranhão são alguns exemplos desses bens já reconhecidos. Referências culturais que são encontradas, predominantemente, em núcleos negros, dentre os quais comunidades quilombolas ${ }^{5}$.

\section{A materialidade do imaterial e a imaterialidade do material}

Será apenas uma coincidência o fato de que, em sua maioria, os bens "materiais" tombados pelo Iphan sejam representativos de determinados segmentos da sociedade brasileira, majoritariamente brancos, católicos e da elite econômica; enquanto os bens "imateriais" registrados pelo Iphan são, por sua vez, representativos de outros segmentos, predominantemente dos indígenas e afrobrasileiros? Tal "materialidade" estaria ausente desses últimos? Decerto, não. Todas as sociedades, de diferentes maneiras, se apropriam, produzem e se relacionam com seus objetos, edificações e corpos. Não há como pensar qualquer "manifestação cultural" sem os seus suportes materiais, sendo os primeiros os próprios corpos de seus agentes. Assim como não há como pensar qualquer "edificação" ou "objeto" sem vinculá-lo àquelas práticas e sistemas de significação que o produziram e o significam - uma igreja só é uma igreja a partir do momento em que ali se constitui como um lugar simbólico e de prática religiosa. Contudo, durante muito tempo a atuação do Iphan como órgão responsável pela seleção e preservação do patrimônio histórico e artístico nacional foi vista, e reiterada pelos seus funcionários, como uma atividade eminentemente técnica realizada predominantemente por arquitetos. Não se notava que tal processo de seleção era substancialmente valorativo e correspondente a determinados padrões estéticos e ideológicos. Foi preciso um caso exemplar para que os embates ideológicos no campo do patrimônio viessem à tona e outras perspectivas passassem a integrar essas políticas. Esse foi o caso do terreiro de candomblé Casa Branca de Salvador, Bahia.

O pedido de tombamento de Casa Branca suscitou diversas discussões no Conselho Consultivo do Iphan, órgão deliberativo responsável por fazer a avaliação da pertinência do reconhecimento de um bem como patrimônio da União. Gilberto Velho, antropólogo que na ocasião fazia parte desse Conselho, expõe a problemática colocada por esse tombamento: 
Quando conselheiros argumentavam que não se podia "tombar uma religião", certamente entendiam que o tombamento de centenas de igrejas e monumentos católicos teria se dado apenas por razões artístico-arquitetônicas, o que não nos parecia correto. Assim, o tombamento de Casa Branca significava a afirmação de uma visão da sociedade brasileira como multiétnica, constituída e caracterizada pelo pluralismo sociocultural. (VELHO, 2006, p. 240)

Como Velho aponta, as razões artístico-arquitetônicas para o tombamento de um bem encobriam os valores e ideologias que balizavam a seleção de bens passíveis de reconhecimento como parte do patrimônio nacional, e consequentemente, como símbolos ou marcos de uma identidade brasileira. Assim, colocava-se como atos bastante distintos o tombamento de uma igreja católica e o tombamento de um terreiro de candomblé.

Maria Cecília Londres Fonseca, ao analisar a sistemática dos processos de tombamento a partir da origem dos pedidos, das justificativas desses e dos pareceres de aprovação ou impugnação, identifica os principais problemas e conflitos inerentes a essa prática. A autora destaca que os processos de tombamento são orientados por concepções socialmente construídas e legitimadas, como as concepções de valor histórico, artístico, excepcional e nacional. Investigando os usos dessas concepções em processos que tratam do tombamento de bens de grupos sociais populares, vinculados a outras tradições culturais que não a luso-brasileira, Fonseca concluiu:

Fica evidente que o processo de atribuição de valor não pode ser reduzido a uma questão técnica. As discussões levantadas por esses (ainda poucos) processos explicitam o caráter ideológico da construção dos patrimônios. (FONSECA, 2005, p. 203)

Nesse sentido, podemos refletir sobre as questões ideológicas envolvidas no reconhecimento dos quilombos como parte do patrimônio cultural nacional. 0 tombamento de apenas dois quilombos históricos e o silêncio nos dossiês de registro sobre os quilombos contemporâneos indicam a manutenção de uma visão passadista de quilombo e o não reconhecimento da atualidade da luta quilombola pelo reconhecimento dos direitos coletivos dos grupos. Para além disso, a 
perspectiva adotada pelo órgão, na qual a cultura é concebida de forma fragmentada, tanto pela separação de suas dimensões "materiais" e "imateriais" como pela categorização dos bens em diferentes livros de tombo - no caso do patrimônio imaterial, a partir das categorias: "saberes", "formas de expressão", "celebrações" e "lugares" -, coloca obstáculos para o reconhecimento do patrimônio cultural de comunidades quilombolas. Com isso, a complexidade de tais contextos, nos quais muitos dos saberes e práticas são inter-relacionados e o vínculo com o território é estruturador de diversas relações, dificilmente é contemplada pelas políticas patrimoniais.

Por fim, conclui-se que a efetividade da proteção e salvaguarda do patrimônio cultural "não consagrado", que começa a ser reconhecido com a criação da área do patrimônio imaterial e do instrumento de registro, passa necessariamente pelo fim das dicotomias que perpetuam uma separação problemática de dimensões material e imaterial - que trabalha a favor do reforço de posicionamentos ideológicos hegemônicos. O tombamento e o registro, os principais instrumentos dessa política, precisam ser repensados de forma articulada para que se contemplem as dimensões imateriais e materiais de todos aqueles bens selecionados como patrimônio cultural nacional. Afinal, o samba, o jongo, a capoeira, o batuque - dentre outras referencias pinçadas pelas políticas de patrimônio cultural - não podem ser compreendidos fora de seus contextos de produção e de todas as redes que relacionam e significam a cultura de um grupo.

\section{Notas}

(1) Cientista social pela UFMG, aluna do Mestrado Profissional em Preservação do Patrimônio Cultural do Instituto do Patrimônio Histórico e Artístico Nacional. E-mail: biaccioly@gmail.com.

(2) Em relação a esse tombamento, considero que seja expressivo do contexto de marginalização e discriminação das religiões afro-brasileiras do período e que o modo como o acervo é ainda hoje conservado (no Museu da Polícia Civil do Rio de Janeiro, com acesso restrito ao público) sintomático da perpetuação dessa situação.

(3) "O Estado protegerá as manifestações das culturas populares, indígenas e afro-brasileiras, e das de outros grupos participantes do processo civilizatório nacional” (§ $1^{\circ}$ do art. 215 da CF88). 
(4) Em 6 de dezembro de 1994 a Medida Privosória ํㅜ 752 transformou o IBPC em Instituto do Patrimônio Histórico e Artístico Nacional.

(5) Embora seja notória a presença e manutenção dessas referências culturais em comunidades quilombolas, em alguns dos dossiês de registro não é sequer citada a existência dessas comunidades.

\section{Referências}

ARRUTI, José Maurício A. O quilombo conceitual: para uma sociologia do "artigo 68". Rio de Janeiro: Koinonia, 2003. Texto para discussão - Projeto Egbé - territórios negros.

ARRUTI, José Maurício. Mocambo: história e antropologia do processo de formação quilombola. Bauru, SP: EDUSC/ANPOCS, 2005.

ASSOCIAÇÃO BRASILEIRA DE ANTROPOLOGIA. Documento do grupo de trabalho sobre comunidades negras rurais. Rio de Janeiro, 1994.

BRASIL. Constituição (1988). Brasília: Senado Federal,1988.

BRASIL. Decreto n. 4887, de 20 de novembro de 2003. Regulamenta o procedimento para identificação, reconhecimento, delimitação, demarcação e titulação das terras ocupadas por remanescentes das comunidades dos quilombos de que trata o art. 68 do Ato das Disposições Constitucionais Transitórias. Brasília, DF, 2003. Disponível em: <http://www.planalto.gov.br/ccivil 03/decreto/2003/d4887.htm>. Acesso em: 6 nov. 2013.

CUNHA, Manuela Carneiro. Cultura com aspas. São Paulo: Cosac \& Naify, 2009.

FONSECA, Maria Cecília Londres. O patrimônio em processo: trajetória da política federal de preservação. Rio de Janeiro: UFRJ, 2005.

FONSECA, Maria Cecília Londres. Referências culturais: base para novas políticas de patrimônio. In: Inventário nacional de referências culturais: manual de aplicações. Brasília: Iphan/Minc, 2000.

GONÇALVES, José Reginaldo Santos. A retórica da perda. Rio de Janeiro: UFRJ, 2002.

HALBWACHS, Maurice. A memória coletiva. São Paulo: Centauro, 2006. 
INSTITUTO DO PATRIMÔNIO HISTÓRICO E ARTÍSTICO NACIONAL. Parecer 47/98 - DEPROT. Brasília, 1998.

LIMA, Pablo Luiz de Oliveira. Sombras de escravos rebeldes. In: CARVALHO, Cláudia S. Rodrigues de; GRANATO, Marcus; BEZERRA, Rafael Zamorano. Um olhar contemporâneo sobre a preservação do patrimônio cultural material. Rio de Janeiro: Museu Histórico Nacional, 2008. p. 158-170.

O'DWYER, Eliane Cantarino. Quilombos: identidade étnica e territorialidade. Rio de Janeiro: FGV, 2002.

SANT'ANNA, Márcia. Escravidão no Brasil: os terreiros de candomblé e a resistência cultural dos povos negros. Disponível em: $<$ http://portal.iphan.gov.br/montarDetalheConteudo.do;jsessionid=1D0B5C9E5EE39C9B5179AFD304 A4C3E9?id=12728\&sigla=Institucional\&retorno=detalhelnstitucional $>$. Acesso em: 17 abr. 2012.

VELHO, Gilberto. Patrimônio, negociação e conflito. Mana, v. 12, n.1, p. 237-248, 2006. Disponível em: <http://www.scielo.br/pdf/mana/v12n1/a09v12n1.pdf>. Acesso em: 7 nov. 2013.

VIEIRA FILHO, Dalmo. Sobre o tombamento dos quilombos: atualizando a discussão. Brasília: Iphan, s.d. 